\title{
Information Architecture of Web-Based Interventions to Improve Health Outcomes: Systematic Review
}

Jillian Pugatch ${ }^{1}$, MPH; Emily Grenen ${ }^{1}$, MSc; Stacy Surla ${ }^{1}$, MA; Mary Schwarz ${ }^{2}$, BA; Heather Cole-Lewis ${ }^{3}, \mathrm{PhD}$, $\mathrm{MPH}$

${ }_{1}^{1}$ ICF, Rockville, MD, United States

${ }^{2}$ ICF, Fairfax, VA, United States

${ }^{3}$ Johnson \& Johnson Health and Wellness Solutions, Inc, New Brunswick, NJ, United States

Corresponding Author:

Jillian Pugatch, MPH

ICF

530 Gaither Road

Suite 500

Rockville, MD, 28770

United States

Phone: 13015720856

Email: jillian.pugatch@icf.com

\section{Abstract}

Background: The rise in usage of and access to new technologies in recent years has led to a growth in digital health behavior change interventions. As the shift to digital platforms continues to grow, it is increasingly important to consider how the field of information architecture (IA) can inform the development of digital health interventions. IA is the way in which digital content is organized and displayed, which strongly impacts users' ability to find and use content. While many information architecture best practices exist, there is a lack of empirical evidence on the role it plays in influencing behavior change and health outcomes.

Objective: Our aim was to conduct a systematic review synthesizing the existing literature on website information architecture and its effect on health outcomes, behavioral outcomes, and website engagement.

Methods: To identify all existing information architecture and health behavior literature, we searched articles published in English in the following databases (no date restrictions imposed): ACM Digital Library, CINAHL, Cochrane Library, Google Scholar, Ebsco, and PubMed. The search terms used included information terms (eg, information architecture, interaction design, persuasive design), behavior terms (eg, health behavior, behavioral intervention, ehealth), and health terms (eg, smoking, physical activity, diabetes). The search results were reviewed to determine if they met the inclusion and exclusion criteria created to identify empirical research that studied the effect of IA on health outcomes, behavioral outcomes, or website engagement. Articles that met inclusion criteria were assessed for study quality. Then, data from the articles were extracted using a priori categories established by 3 reviewers. However, the limited health outcome data gathered from the studies precluded a meta-analysis.

Results: The initial literature search yielded 685 results, which was narrowed down to three publications that examined the effect of information architecture on health outcomes, behavioral outcomes, or website engagement. One publication studied the isolated impact of information architecture on outcomes of interest (ie, website use and engagement; health-related knowledge, attitudes, and beliefs; and health behaviors), while the other two publications studied the impact of information architecture, website features (eg, interactivity, email prompts, and forums), and tailored content on these outcomes. The paper that investigated IA exclusively found that a tunnel IA improved site engagement and behavior knowledge, but it decreased users' perceived efficiency. The first study that did not isolate IA found that the enhanced site condition improved site usage but not the amount of content viewed. The second study that did not isolate IA found that a tailored site condition improved site usage, behavior knowledge, and some behavior outcomes.

Conclusions: No clear conclusion can be made about the relationship between IA and health outcomes, given limited evidence in the peer-reviewed literature connecting IA to behavioral outcomes and website engagement. Only one study reviewed solely manipulated IA, and we therefore recommend improving the scientific evidence base such that additional empirical studies investigate the impact of IA in isolation. Moreover, information from the gray literature and expert opinion might be identified 
and added to the evidence base, in order to lay the groundwork for hypothesis generation to improve empirical evidence on information architecture and health and behavior outcomes.

(J Med Internet Res 2018;20(3):e97) doi: 10.2196/jmir.7867

\section{KEYWORDS}

information architecture; systematic review; health outcomes; behavior change; health behavior

\section{Introduction}

With the rise of new technology and digitization of our physical information environments, it is important to understand the role of digital information organization on user outcomes. This may be particularly important for the information architecture (IA) of Web content [1]. While no one definition of IA exists, it generally encompasses the organization of digital information, the labeling of information, and the navigation and search capabilities within a digital information space. The goal of IA is to build digital sites that enhance the user experience-in particular, the user's ability to find and use content [2].

IA is vital to website development. In commercial settings, good IA can enhance the ability of employees and customers to find information and decrease costs of Web redesign and maintenance [2]. However, IA is less often discussed in the context of digital spaces for behavior change and health outcomes. Moreover, IA best practices for commercial settings may not translate to health-related ones, where user needs are entirely different [2]. A user seeking information that is factual, concrete, and that they know exists (eg, the price of a new computer or the weekend forecast) will benefit from different site architecture than the user who wants to quit smoking or manage weight loss. In the latter scenarios, the information sought may be complicated and unfamiliar; the user may not even know exactly what information they should be seeking. Thus, while many IA recommendations exist, there is still a lack of empirical evidence for the role that IA plays in Web-based health behavior interventions.

Digital health interventions that mention IA primarily focus on navigation systems [3-5]. Generally, navigation systems concern the relationships among information or content at different levels-such as Web pages or sections. Structures can be hierarchical (top-down approach, with broader subjects encompassing smaller ones), matrix (movement along multiple dimensions), organic (free movement or exploration), or tunnel (sequential or linear organization) [6].

Many experts in the field recommend and implement a tunnel (or tunnel hybrid) design for behavior change websites. A recent systematic review of Web-based health intervention studies showed that tunneling structures were used in $90 \%$ of interventions reviewed. Of the interventions reviewed, all of those with a mental health focus used tunnel designs [7]. Users of websites with a tunnel design navigate in a sequential fashion to optimize the ordering of information and maximize the effectiveness of the site, in much the same way that one would read a novel or watch a television series from start to finish [1]. An example of tunnel design might be an online app that takes the user through a series of steps in a sequential order (eg, the app for health insurance on the American HealthCare.gov website), or a site with an e-learning module where lessons are presented in a predetermined order [1,8]. A tunnel experience is less likely to overwhelm users with information and options; it simplifies information consumption by defining what the user sees and when. In addition, tunnel design has the capacity to provide tailored "remedial" loops for users who do not pass certain knowledge test "check-points" or assessments [1]. In general, this type of feedback and reinforcement personalizes the experience and helps the individual progress through an intervention program. Evidence shows that personalized Web interventions are more efficacious in behavior change [1,9].

A hybrid design that includes elements of tunnel design provides an opportunity to give users more structure and guidance while also allowing a user to break free from a "locked" information structure if they so choose [1]. A website with a hybrid design might, for example, offer the user a table of contents that allows that individual to view website pages in any order. However, this same site might also include links within certain pages that direct users to a logical next step, thereby providing an element of tunnel design (eg, the National Institute of Justice's Laboratory Safety Training website) [10]. A hybrid tunnel design has the capacity to offer the user various ways of consuming the information, which may incentivize the user to take a more active role in their learning experience rather than simply turning pages, which is a risk with tunnel-only designs [1]. Hybrid design may also reduce attrition rate of a full tunnel design, as it does not deter individuals who may find the tunnel design too inflexible [1].

Conversely, free-form matrix - also known as organic-and hierarchical designs are less suitable for users unfamiliar with the content area (as is often the case for users of behavior change sites) because the freedom to explore information may make it difficult to navigate [1]. Additionally, these designs can make it more challenging for users to retrace their information search in order to review something previously seen [1].

Despite the aforementioned recommendations and the attention IA has received in the commercial sector, IA is largely a missed opportunity in the health behavior field. Most digital health intervention research describes the studies but fails to address the actual features of the Web tools being used, such as their IA [11-13]. Yet, understanding and implementing IA designs that best promote behavior change may be a simple and sustainable way to significantly improve the efficacy of digital interventions.

Thus, this review synthesizes the existing literature on website IA in the context of Web-based health interventions. We examine whether manipulating the information architecture of 
Web-based health interventions influences website use, health behaviors, and outcomes.

\section{Methods}

\section{Inclusion and Exclusion Criteria}

Articles were considered eligible if they met all inclusion criteria. In addition to being peer-reviewed and published in English, studies were included if they were (1) a randomized controlled trial (RCT), (2) an assessment of the effect of one type of IA compared to any other type of IA, (3) an intervention delivered in a Web-based setting, and (4) included either a primary health outcome measure (eg, disease status) or a secondary, proximal health outcome measure including change in knowledge, attitudes, or beliefs (eg, hepatitis knowledge) relating to the target health behavior, behavior change (eg, number of cigarettes smoked), website engagement (eg, number of pages visited), or attitudes towards the website (eg, perceived user control). No date restrictions were imposed. Interventions could address any health issue (eg, mental health, chronic conditions, and communicable diseases). Studies were included only if interventions were Web-based; interventions that focused on mobile apps or games, for example, were excluded.

\section{Search Strategy}

Literature searches were conducted on March 30, 2015. The following electronic databases were searched: ACM Digital Library, CINAHL, Cochrane Library, Google Scholar, Ebsco, and PubMed. The search terms used included information terms (eg, information architecture, interaction design, persuasive design), behavior terms (eg, health behavior, behavioral intervention, ehealth), and health terms (eg, smoking, physical activity, diabetes) (see Multimedia Appendix 1).

Eligibility assessment was performed independently by 2 reviewers. Disagreements between reviewers were resolved by consensus that included a third reviewer.

\section{Data Extraction and Synthesis}

A data extraction form was developed based on a priori categories established by 3 reviewers. Due to the small number of articles included in the review, this form was piloted on the three publications included in the systematic review.

Information was extracted from each included study on (1) characteristics of participants (including age, disease/behavior status), (2) type of intervention, (3) types of information architecture manipulated, (4) duration of the study, (5) website engagement outcomes, (6) knowledge, attitudes, and beliefs outcomes, and (7) health outcomes.

To determine the validity of eligible randomized trials, the pair of reviewers used the Cochrane Collaboration tool for assessing risk of bias in individual studies [14]. Disagreements in quality assessments were resolved by discussion between the 2 reviewers.

\section{Results}

\section{Findings}

Figure 1 illustrates the number of studies identified, screened, and included in this literature review [15]. The database literature search produced 782 citations. After duplicate citations were removed and the abstracts were reviewed, 17 citations met the inclusion criteria. The full text of these remaining citations were reviewed, and 14 were excluded because of study design (non-RCTs), a lack of IA manipulation, a lack of primary or secondary health outcome measures, or because they studied a non Web-based platform. Three articles were included in this systematic review [16-18].

\section{Risk of Bias Assessment}

The risk of bias criteria and outcomes are described in Table 1 . Overall, risk of bias for all studies was low. Two studies failed to clearly report their method of random sequence generation $[17,18]$, and one failed to report methods of allocation concealment and blinding of participants and personnel [17].

\section{Study Characteristics}

A summary of notable study characteristics is reported in Table 2. Sample sizes ranged from 561 [16] to 2523 [17] participants. One study was conducted in the United States [17], one in the Netherlands [18], and the third in Germany [16]. All studies were published in English.

\section{Participants}

Although all three studies lost participants to follow-up, only Weymann et al noted selective dropout, which occurred among participants with chronic lower back pain [16]. Those in the tailored condition were younger (mean 48.0, SD 12.9) and had higher education defined by having more than 10 years of education $(119 / 190,62.6 \%)$ than those in the control (age: mean 52.0, SD 12.7, $P=.015$; education: $94 / 188,50.0 \%, P=.021)$. This study conducted intention-to-treat (ITT) and available cases (AC) analyses in order to determine the extent to which selection bias may have impacted the results.

\section{Intervention Characteristics and Outcomes}

The manipulation solely of IA was studied in only one publication [18], making it difficult to attribute the other two studies' results to the difference in IA. The two other studies manipulated website features (eg, interactivity, email prompts, and forums) and tailored content in addition to IA. All studies assessed some form of tunnel architecture against an organic architecture. Outcomes assessed included number of pages visited, time on site, website attrition, knowledge, perceived user control, perceived control, decisional conflict, patient empowerment, preparation for decision making, and change in knowledge.

Given that only one of the three publications assessed the isolated effect of IA, intervention characteristics and effect of IA on outcomes of interest are presented by study and categorized by whether the effect of IA was isolated. Table 3 includes more details regarding the studies' designs, results, and conclusions. 


\section{Interventions Assessing the Isolated Effect of Information Architecture}

\section{Crutzen et al Intervention Characteristics}

The Crutzen et al study involved two versions of a website with different information architectures and a no-website control group [18]. This publication assessed tunnel versus organic architecture.

One intervention group used a website about hepatitis with tunnel design. The pages on this site could be viewed only in a predetermined order and pages could not be skipped. The second group visited a freedom of choice (organic) site with identical content and the same number of pages as the tunnel version, but users had the ability to skip pages.

\section{Crutzen et al Outcomes}

Participants in the tunnel condition visited more pages (mean 11.4) compared to those in the freedom of choice condition (mean 7.4, $P<.001$ ). Users in the tunnel condition also spent more time on the site the than freedom of choice users $(3: 50$ minutes compared to $2: 38$ minutes; $F_{1,452}=6.32, P=.01$ ).

Less user control had a negative effect on perceived website efficiency $(P<.01)$, but a positive effect on knowledge gained
$(P<.001)$. Participants in the tunnel group scored higher on hepatitis knowledge compared with the freedom of choice group $(P<.001)$.

\section{Interventions Assessing the Non-Isolated Effect of Information Architecture}

\section{Danaher et al Intervention Characteristics}

Danaher et al exposed smokeless tobacco users to a Basic and an Enhanced website for smokeless tobacco cessation called Chewfree.com [17]. The article assessed hybrid tunnel versus organic architecture. The Enhanced condition offered a tailored and interactive Web-based program that included text-based information, video-based testimonials, printable resources, interactive activities, annotated links to other website resources, and two Web forums. The Enhanced site used five navigational pages (one of which used a hybrid design that incorporated tunneling). The Basic condition represented a subset of the content presented in the Enhanced condition and included text-based content using four navigational pages. It also offered a printable self-help smokeless tobacco cessation booklet, printable cessation resource, and annotated links to other recommended websites for tobacco cessation. 
Figure 1. Preferred Reporting Items for Systematic Reviews and Meta-Analyses flow diagram. RCT: randomized controlled trial; IA: information architecture.
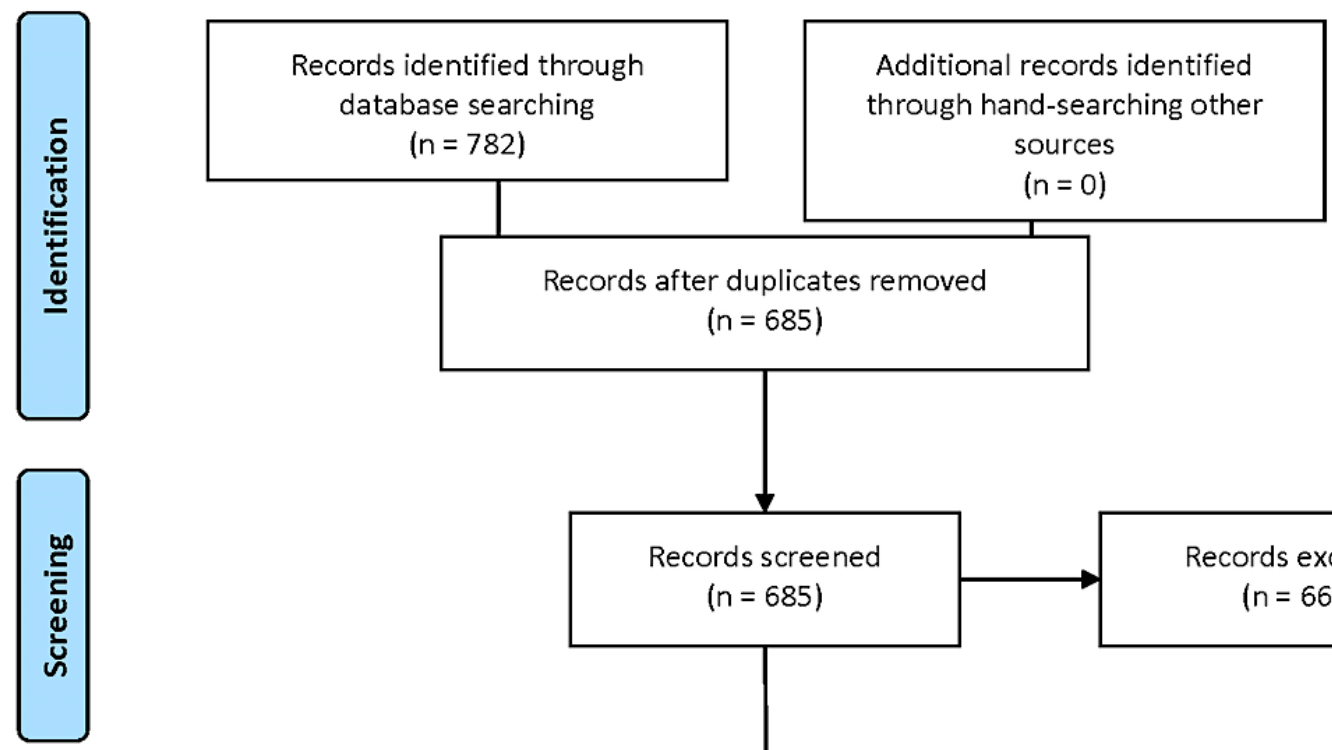

Records after duplicates removed $(n=685)$
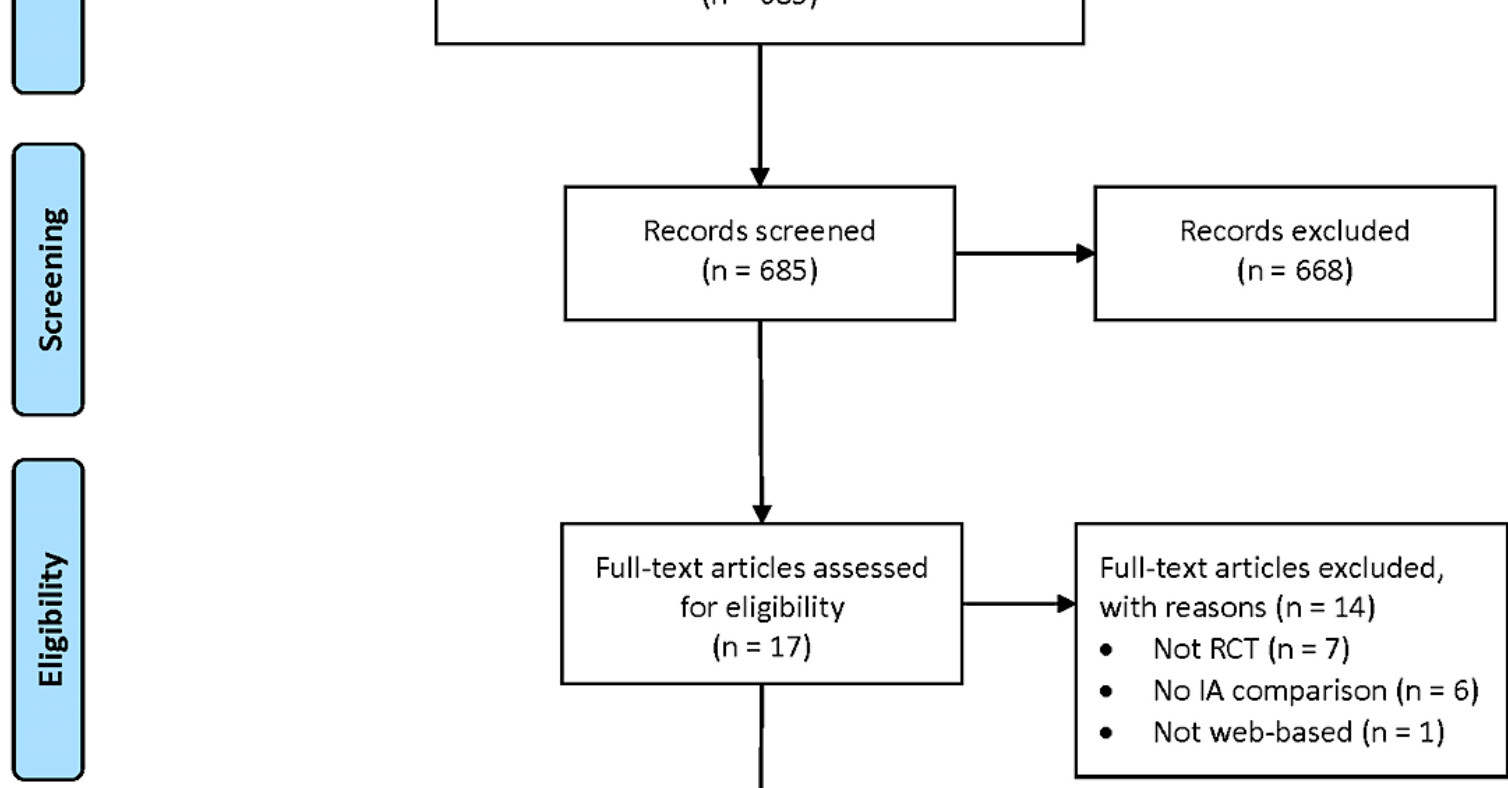

홍

Studies included in qualitative synthesis $(n=3)$ 
Table 1. Risk of bias assessment ${ }^{\mathrm{a}}$ for individual studies.

\begin{tabular}{|c|c|c|c|c|c|c|}
\hline \multirow[t]{2}{*}{ Criteria } & \multicolumn{2}{|c|}{ Weymann et al [16] } & \multicolumn{2}{|c|}{ Danaher et al [17] } & \multicolumn{2}{|c|}{ Crutzen et al [18] } \\
\hline & $\begin{array}{l}\text { Risk of } \\
\text { bias }\end{array}$ & Support for judgment & $\begin{array}{l}\text { Risk of } \\
\text { bias }\end{array}$ & Support for judgment & $\begin{array}{l}\text { Risk of } \\
\text { bias }\end{array}$ & Support for judgment \\
\hline $\begin{array}{l}\text { Random sequence } \\
\text { generation }\end{array}$ & Low & $\begin{array}{l}\text { Simple randomization of par- } \\
\text { ticipants performed by a soft- } \\
\text { ware program }\end{array}$ & Unclear & $\begin{array}{l}\text { No description of the } \\
\text { methodology to generate allo- } \\
\text { cation sequence }\end{array}$ & Unclear & $\begin{array}{l}\text { No description of the } \\
\text { methodology to generate allo- } \\
\text { cation sequence }\end{array}$ \\
\hline $\begin{array}{l}\text { Blinding of outcomes } \\
\text { assessment }\end{array}$ & Low & $\begin{array}{l}\text { Outcomes all collected via } \\
\text { self-reported questionnaires. }\end{array}$ & Low & $\begin{array}{l}\text { Website use and engagement } \\
\text { comprised all outcomes mea- } \\
\text { sured, which were calculated } \\
\text { via an automated computer } \\
\text { program. }\end{array}$ & Low & $\begin{array}{l}\text { All outcomes were collected } \\
\text { via a computer server (web- } \\
\text { site use) or via self-reported } \\
\text { questionnaires completed on- } \\
\text { line. }\end{array}$ \\
\hline $\begin{array}{l}\text { Incomplete outcome } \\
\text { data }\end{array}$ & Medium & $\begin{array}{l}\text { Although authors stated that } \\
\text { "attrition was comparatively } \\
\text { low for an online trial," they } \\
\text { found evidence for selective } \\
\text { dropout between the control } \\
\text { and intervention conditions. }\end{array}$ & Low & $\begin{array}{l}\text { Only about } 6 \% \text { of participants } \\
\text { were not included in the anal- } \\
\text { yses. This included partici- } \\
\text { pants who never visited their } \\
\text { assigned website or returned } \\
\text { only to complete online assess- } \\
\text { ments. }\end{array}$ & Low & $\begin{array}{l}\text { Relatively small dropout rate } \\
\text { between pre-test and follow- } \\
\text { up, and authors reported that } \\
\text { there was neither selective } \\
\text { dropout nor a difference in } \\
\text { dropout between conditions. }\end{array}$ \\
\hline Selective reporting & Low & $\begin{array}{l}\text { Data for all outcomes de- } \\
\text { scribed in the study proto- } \\
\text { cols }{ }^{\text {b,c }} \text { were reported. }\end{array}$ & Low & $\begin{array}{l}\text { Data from all outcomes indi- } \\
\text { cated in the Methods section } \\
\text { reported in the Results sec- } \\
\text { tion. }\end{array}$ & Low & $\begin{array}{l}\text { Data from all outcomes indi- } \\
\text { cated in the Methods section } \\
\text { reported in the Results sec- } \\
\text { tion. }\end{array}$ \\
\hline Other bias & Low & None identified. & Low & None identified. & Low & None identified. \\
\hline
\end{tabular}

${ }^{a}$ Risk of bias was categorized as low, medium, or high based on whether reviewers thought the methods or descriptions indicated a low, medium, or high risk. "Unclear" risk of biases was noted for studies that lacked a description of that domain.

$\mathrm{b}_{[19] .}$

${ }^{\mathrm{c}}[20]$.

\section{Danaher et al Outcomes}

Specific tunnel elements and IA were not isolated in this intervention. The Enhanced site generated more usage. Participants in the enhanced condition made more visits and spent more time on the site than participants in the Basic condition $(P<.001)$. Users in the Enhanced condition continued to use the site for more days than Basic website users $(P<.001)$. Interestingly, more cessation content was visited in the Basic condition, though the study authors note that this could be due to the same content being difficult to find in the Enhanced site.

\section{Weymann et al Intervention Characteristics}

Weymann et al compared a tailored and interactive site with some tunneling elements to a control site without tunneling [16]. The study assessed dialogue-based and tunnel versus organic architecture. There were intervention and control sites for people with type 2 diabetes and chronic lower back pain for a total of four conditions. The look of the websites (colors, font, figures, and pictures) was identical in all conditions, and participants could view sites as often as they wished. 
In the tailored conditions, the delivery format was a dialogue-based, tunnel design. The dialogue aspect of the design attempts to imitate a conversation with a health professional. Various check-points assessed user knowledge and attitude toward a topic, and content was then modified according to their answer. Users were given limited control over the sequence in which they viewed content-although they were permitted to pick from one of several options at the end of each text passage. On the control websites, the content was not tailored and was not presented in a dialogue format. In contrast to the tailored, interactive version, the control website users were given freedom to view content in any order by selecting topics from a menu.

\section{Weymann et al Outcomes}

Analyses and findings of this study did not explore IA specifically. In this study, the tailored and tunnel conditions spent more time on the site (51.16 minutes) than the control groups (37.6 minutes) $(P<.001)$. Results for the other outcomes are as follows:

- Knowledge after the first visit ITT: no significant difference $(P=.53)$; AC: tailored group had significantly more knowledge $(P=.02)$ than control

- Patient empowerment ITT: no significant difference; AC: tailored group had better emotional well-being (a subscale of empowerment) than control $(P=.009)$

- Decisional conflict disease main effect for ITT and AC

- Preparation for decision making ITT: no significant difference; $\mathrm{AC}$ : disease main effect $(P=.02)$

Content tailoring and interactivity may increase knowledge and reduce health-related negative effects in persons who use interactive health communication apps.

Table 2. Characteristics of included studies.

\begin{tabular}{|c|c|c|c|c|c|}
\hline Study & Intervention arms & Population & Sample size & Health concern & Outcome measures $^{\mathrm{a}}$ \\
\hline $\begin{array}{l}\text { Weymann et } \\
\text { al [16] }\end{array}$ & $\begin{array}{l}\text { Tunnel condition: Tunnel } \\
\text { design and tailored content } \\
\text { Control condition: Free- } \\
\text { form navigation website } \\
\text { with untailored content not } \\
\text { presented in a dialogue for- } \\
\text { mat }\end{array}$ & $\begin{array}{l}\text { Adults in Germany with } \\
\text { access to internet and suffi- } \\
\text { cient computer/internet lit- } \\
\text { eracy. Participants had ei- } \\
\text { ther a self-reported diagno- } \\
\text { sis of type } 2 \text { diabetes or } \\
\text { chronic low back pain. }\end{array}$ & $\begin{array}{l}\text { Baseline }(n=561) \text { : Tunnel } \\
\text { condition } n=283 ; \text { Control } \\
\text { condition } n=278 \\
\text { Follow-up }(n=295) \text { : Tun- } \\
\text { nel condition } n=146 \text {; Con- } \\
\text { trol condition } n=149\end{array}$ & $\begin{array}{l}\text { Type } 2 \text { diabetes; } \\
\text { Chronic lower } \\
\text { back pain }\end{array}$ & $\begin{array}{l}\text { (1) Time on website, (2) } \\
\text { Knowledge after first web- } \\
\text { site visit, (3) Decisional } \\
\text { conflict after 1st website } \\
\text { visit, (4) Preparation for } \\
\text { decision making after 1st } \\
\text { website visit, (5) Patient } \\
\text { empowerment at 3-month } \\
\text { follow-up }\end{array}$ \\
\hline $\begin{array}{l}\text { Danaher et } \\
\text { al [17] }\end{array}$ & $\begin{array}{l}\text { Enhanced condition: Hybrid } \\
\text { tunnel design website with } \\
\text { interactive, tailored, rich } \\
\text { media } \\
\text { Control condition: Static, } \\
\text { text-based website with free } \\
\text { navigation to all content }\end{array}$ & $\begin{array}{l}\text { Adult smokeless tobacco } \\
\text { users in the United States. }\end{array}$ & $\begin{array}{l}\text { Baseline }(n=2523) \text { : En- } \\
\text { hanced condition } n=1260 \text {; } \\
\text { Control condition } n=1263\end{array}$ & $\begin{array}{l}\text { Smokeless tobac- } \\
\text { co use }\end{array}$ & $\begin{array}{l}\text { (1) Website visits at } \mathrm{T} 1 \text {, } \\
\mathrm{T} 2 \text {, and } \mathrm{T} 3, \text { (2) Time on } \\
\text { website at } \mathrm{T} 1, \mathrm{~T} 2 \text {, and } \mathrm{T} 3 \text {, } \\
\text { (3) Website attrition from } \\
\mathrm{T} 1-\mathrm{T} 3\end{array}$ \\
\hline $\begin{array}{l}\text { Crutzen et al } \\
{[18]}\end{array}$ & $\begin{array}{l}\text { Tunnel condition: Website } \\
\text { with tunnel design and less } \\
\text { user control } \\
\text { Free-form condition: Free- } \\
\text { dom of choice design where } \\
\text { users had ability to skip } \\
\text { pages } \\
\text { Control condition: No expo- } \\
\text { sure to website }\end{array}$ & $\begin{array}{l}\text { Adult internet users in the } \\
\text { Netherlands. }\end{array}$ & $\begin{array}{l}\text { Baseline ( } n=668) \text { : Tunnel } \\
\text { condition: } n=226 \text {; Free- } \\
\text { form condition: } n=228 \text {; } \\
\text { Control: } n=214 \\
\text { Follow-up }(n=571) \text { : Tun- } \\
\text { nel condition: } n=200 \text {; Free- } \\
\text { form condition: } n=193 \text {; } \\
\text { Control: } n=178\end{array}$ & Hepatitis & $\begin{array}{l}\text { (1) Time on website at T0, } \\
\text { (2) Number of pages } \\
\text { viewed at T0, (3) Per- } \\
\text { ceived user control at T1, } \\
\text { (4) User perceptions at T1, } \\
\text { (4) Change in hepatitis } \\
\text { knowledge from T0-T2 }\end{array}$ \\
\hline
\end{tabular}

${ }^{\mathrm{a}} \mathrm{T} 0=$ baseline, $\mathrm{T} 1=$ time $1, \mathrm{~T} 2=$ time 2 , and $\mathrm{T} 3=$ time 3 , when user data were collected. 
Table 3. Results and conclusions of included studies.

\begin{tabular}{|c|c|c|c|c|}
\hline Author & Data collection points & Website use results & Knowledge, attitudes, beliefs results & Conclusion \\
\hline $\begin{array}{l}\text { Weymann et } \\
\text { al [16] }\end{array}$ & $\begin{array}{l}\text { T1: Immediately after 1st } \\
\text { website visit, T2: 3-month } \\
\text { follow-up }\end{array}$ & $\begin{array}{l}\text { Time on website: Tunnel } \\
\text { condition mean } 51.2 \text { min; } \\
\text { Control condition mean } 37.6 \\
\text { min }(P<.001)\end{array}$ & $\begin{array}{l}\text { Knowledge after 1st visit: ITT analy- } \\
\text { sis=Tailored condition mean } 77.9 \text {; Control } \\
\text { condition mean } 76.3(P=.53) \text {. } \\
\mathrm{AC}^{\mathrm{b}} \text { analysis=Tailored condition mean } \\
79.1 \text {; Control condition mean } 75.2(P=.02) \\
\text { Decisional conflict after 1st visit: No sig- } \\
\text { nificant intervention main effects for AC } \\
\text { or ITT analyses. } \\
\text { Preparation for decision making after 1st } \\
\text { visit: No significant intervention main ef- } \\
\text { fects for AC or ITT analyses. }\end{array}$ & $\begin{array}{l}\text { Participants spent more time } \\
\text { with tunnel site than the con- } \\
\text { trol. In the ITT analyses, this } \\
\text { did not result in more knowl- } \\
\text { edge or empowerment. Sensitiv- } \\
\text { ity analyses (AC) showed that } \\
\text { participants in tunnel condition } \\
\text { displayed more knowledge and } \\
\text { emotional well-being. Howev- } \\
\text { er, on other measures of patient } \\
\text { empowerment, there was no } \\
\text { difference between the } 2 \text { condi- } \\
\text { tions. }\end{array}$ \\
\hline
\end{tabular}

Patient empowerment at 3-month followup: ITT analysis=No significant intervention main effect or interaction.

$\mathrm{AC}$ analysis=Intervention main effect for Emotional Well-being (subscale of patient empowerment). Tailored condition mean 68.5; Control condition mean 60.0 $(P=.009)$.

Danaher et T1: 6 weeks after enrollal [17] ment, T2: 3 months after enrollment, T3: 6 months after enrollment

Crutzen et al T0: Pretest, T1: Immediately [18]

\begin{abstract}
Website visits: Enhanced condition made more visits ( $z=-16.64, P<.001,2$-tailed).

Time on website: Enhanced condition spent more time viewing website content $(z=-17.63, P<.001,2$-tailed $)$.

Website attrition: Enhanced condition showed slower attrition $(P<.001$ for both logrank and Breslow tests).
\end{abstract}

Time on website: Tunnel condition mean 3:50 min; Free-form condition mean $2: 38 \min \left(F_{1}, 452=6.32\right.$, $P=.01)$.

Number of pages visited:

Tunnel condition mean 11.4 pages; Free-form condition mean 7.4 pages $\left(F_{1,452}=171.49, P<.001\right)$
$\mathrm{N} / \mathrm{A}^{\mathrm{c}}$

Study suggests that hybrid tunnel IA may encourage higher participant engagement with website content than free-form IA. Engagement measures are important in understanding program effectiveness. However, the study is limited in that it does not directly measure behavioral outcomes.

Perceived control: Free-form condition higher mean 5.2; Tunnel condition mean $3.9\left(F_{1,452}=134.32, \mathrm{I}<.001\right)$

Change in hepatitis knowledge: Tunnel condition pretest mean 5.0 , posttest mean 8.2; Free-form pretest mean 5.4, posttest mean 7.2; Control condition pretest mean 5.4 , posttest mean $5.6\left(F_{2,567}=47.24\right.$,

$P<.001)$. All pairwise comparisons significant $(P<.001)$.

\footnotetext{
aTT: intention-to-treat.

${ }^{\mathrm{b}} \mathrm{AC}$ : available cases.

${ }^{\mathrm{c}} \mathrm{N} / \mathrm{A}$ : not applicable.
}

\section{Discussion}

\section{Principal Findings}

Given the limited body of evidence connecting IA to behavioral outcomes and website engagement, no clear conclusions can be made about the relationship between IA and health outcomes. Moreover, several weaknesses in the design of the studies identified make it challenging to generalize results. Only one of the articles, for example, explicitly and empirically manipulated IA by itself [18]. The other studies included other manipulations to website features and tailoring, making it difficult to attribute the results to the difference in IA. Loss to follow-up also makes it difficult to determine whether outcomes resulted from the intervention itself or simply bias [16]. Future empirical research on IA necessitates more robust study designs that isolate the effect of IA and minimize loss to follow-up. Adopting a more nuanced study design approach may even allow researchers to isolate IA while testing other features of an intervention in an RCT. For example, the Sequential Multiple Assignment Randomized Trials (SMART) design for adaptive interventions - in which participants move through multiple 
stages of an intervention and get reassigned to several intervention options-might offer an opportunity to test IA features tailored to particular users depending on their behaviors and needs within the context of a larger intervention trial [21].

The publications in this review did not assess health outcomes-instead they focused on more proximal outcomes such as behavior change and website engagement. It is generally accepted that some level of engagement with a digital intervention is necessary in order to achieve any benefit [22,23], and as such, engagement is often used as a proxy indicator of behavior change or health outcomes. However, engagement measures are not as robust as behavior change or health outcomes (longer engagement might, for example, reflect difficulties in understanding or navigating through the site), and health practitioners and clinicians should collaborate with developers to conduct randomized trials with health outcomes, in order to improve the body of literature on IA.

\section{Strengths and Limitations}

There were some limitations to the review process itself. First, we did not prospectively register our literature review, thereby risking duplication. Also, because search terms attempted to capture websites relating to such a broad topic (ie, health behavior change), it is possible that despite the long list of health terms included, we missed relevant IA and heath behavior change studies.

Despite these limitations, the results of the Crutzen et al study do suggest that less user control (ie, tunnel design) may increase website use and knowledge gained [18]. Less user control may have more impact in a health behavior change context for a variety of reasons [1]. First, a tunnel experience may avoid overwhelming users with too many options by controlling what the user sees and when. In addition, tunnel design can provide a more tailored user experience by tracking users' progress and knowledge attainment (via tests or assessments) and delivering appropriate content accordingly [1]. Feedback and reinforcement not only personalize the user experience but also help the individual progress through an intervention program and adopt a behavior change [1,9]. The Weymann et al study included some of these tailoring elements; it is certainly possible that this attributed to the higher engagement levels in the intervention group.

\section{Future Considerations}

More research is needed to explore whether tunneling can improve user engagement and knowledge and to understand how it impacts behavior outcomes. Additionally, the studies identified here examine only navigation systems (specifically, tunneling versus organic design), which is just one component of information architecture. Future research should consider the effectiveness of other IA organizing designs (ie, hierarchical and matrix design), as well as other IA elements, such as labeling systems (ie, how information is represented). Some research is beginning to explore the effect of enhanced search systems (ie, how users look for information) within a health-related website [24].

Future reviews might also consider a larger scope of literature. For our purposes, we considered only peer-reviewed RCTs. However, there may be a body of gray literature, albeit less robust, on the subject of IA for Web-based health interventions that could be worth investigating given the lack of evidence found here.

The limited evidence base found in this review demonstrates that IA is a largely unstudied aspect of the health behavior field. If a robust evidence base is established and effective IA designs for health behavior change are identified, the development of Web-based interventions could be streamlined. In addition to improved intervention efficacy, evidence-based IAs could free up resources like time and money to enhance other aspects of the intervention such as graphic design, user experience, marketing, or evaluation. Also, the use of A/B or pre-post testing through automated digital platforms could make building an evidence base more feasible.

\section{Conclusion}

Due to the limited evidence base, few claims can be made about the relationship between IA and health and behavior outcomes. There is support for the effect of tunneling on user engagement and knowledge, but more research is needed to support this claim.

This synthesis of information will provide guidance to practitioners designing websites for health behavior and health outcomes. We hope this serves as a starting point for hypothesis generation to improve empirical evidence on IA and health and behavior outcomes.

\section{Acknowledgments}

This work was funded by the National Cancer Institute's Tobacco Control Research Branch of the National Institutes of Health, National Cancer Institute contract \#HHSN261201400002B and \#HHSN26100007. National Cancer Institute staff did not coauthor this manuscript but did have a limited role in study design and decision to publish.

The authors would like to thank Erik Augustson, $\mathrm{PhD}, \mathrm{MPH}$, and Yvonne Hunt, $\mathrm{PhD}$, MPH, for their contributions to the study.

\section{Conflicts of Interest}

None declared.

\section{Multimedia Appendix 1}

Search terms. 
[PDF File (Adobe PDF File), 71KB-Multimedia Appendix 1]

\section{References}

1. Danaher B, McKay H, Seeley J. The information architecture of behavior change websites. J Med Internet Res 2005 May 18;7(2):e12 [FREE Full text] [doi: 10.2196/jmir.7.2.e12] [Medline: 15914459]

2. Rosenfeld L, Morville P, Arango J. In: Rufino A, editor. Information Architecture for the Web and Beyond. 4th edition. Sebastopol, CA: O'Reilly Media, Inc; 2015:1-461.

3. Swartz LHG, Noell JW, Schroeder SW, Ary DV. A randomised control study of a fully automated internet based smoking cessation programme. Tob Control 2006 Feb;15(1):7-12 [FREE Full text] [doi: 10.1136/tc.2003.006189] [Medline: 16436397]

4. Boucher S, Edwards O, Gray A, Nada-Raja S, Lillis J, Tylka T, et al. Teaching Intuitive Eating and Acceptance and Commitment Therapy Skills Via a Web-Based Intervention: A Pilot Single-Arm Intervention Study. JMIR Res Protoc 2016 Oct 14;5(4):e180-e186 [FREE Full text] [doi: 10.2196/resprot.5861] [Medline: 27742602]

5. Danielson CK, McCauley JL, Gros KS, Jones AM, Barr SC, Borkman AL, et al. SiHLEWeb.com: Development and usability testing of an evidence-based HIV prevention website for female African-American adolescents. Health Informatics J 2016 Jun;22(2):194-208 [FREE Full text] [doi: 10.1177/1460458214544048] [Medline: 25167865]

6. Garrett J. In: Nolan MJ, editor. The Elements of User Experience: User-Centered Design for the Web and Beyond. 2nd edition. Berkeley, CA: New Riders; 2011:1-174.

7. Kelders SM, Kok RN, Ossebaard HC, Van Gemert-Pijnen JEWC. Persuasive system design does matter: a systematic review of adherence to web-based interventions. J Med Internet Res 2012 Nov 14;14(6):e152 [FREE Full text] [doi: 10.2196/jmir.2104] [Medline: 23151820]

8. National Cancer Institute. Quiz: Are You Depressed?. 2017. URL: https://smokefree.gov/quiz-are-you-depressed [accessed 2017-12-05] [WebCite Cache ID 6vU8z8hHY]

9. Ritterband LM, Thorndike FP, Cox DJ, Kovatchev BP, Gonder-Frederick LA. A behavior change model for internet interventions. Ann Behav Med 2009 Aug;38(1):18-27 [FREE Full text] [doi: 10.1007/s12160-009-9133-4] [Medline: 19802647]

10. National Institute of Justice. 2017. Training: Laboratory Safety Programs URL: labsafety.training.nij.gov [accessed 2018-03-14] [WebCite Cache ID 6xuwOlqq5]

11. Greenhalgh T, Russell J. Why do evaluations of eHealth programs fail? An alternative set of guiding principles. PLoS Med 2010 Nov 02;7(11):e1000360 [FREE Full text] [doi: 10.1371/journal.pmed.1000360] [Medline: 21072245]

12. World Health Organization. New horizons for health through mobile technologies (Global Observatory for eHealth Series, Volume 3). Geneva, Switzerland: World Health Organization; 2011:1-102.

13. Adibi S, editor. Mobile Health: A technology roadmap. Switzerland: Springer; 2015:1-1172.

14. Higgins J. Cochrane Handbook for Systematic Reviews of Interventions Version 5. 2011. URL: http://handbook-5-1. cochrane.org/ [accessed 2017-12-05] [WebCite Cache ID 6vUC9bJwf]

15. Moher D, Liberati A, Tetzlaff J, Altman D, PRISMA Group. Preferred reporting items for systematic reviews and meta-analyses: the PRISMA statement. Ann Intern Med 2009 Aug 18;151(4):264-269, W64. [Medline: 19622511]

16. Weymann N, Dirmaier J, von Wolff A, Kriston L, Härter M. Effectiveness of a Web-based tailored interactive health communication application for patients with type 2 diabetes or chronic low back pain: randomized controlled trial. J Med Internet Res 2015 Mar 03;17(3):e53 [FREE Full text] [doi: 10.2196/jmir.3904] [Medline: 25736340]

17. Danaher BG, Boles SM, Akers L, Gordon JS, Severson HH. Defining participant exposure measures in Web-based health behavior change programs. J Med Internet Res 2006 Aug 30;8(3):e15 [FREE Full text] [doi: 10.2196/jmir.8.3.e15] [Medline: 16954125]

18. Crutzen R, Cyr D, de Vries NK. The role of user control in adherence to and knowledge gained from a website: randomized comparison between a tunneled version and a freedom-of-choice version. J Med Internet Res 2012 Mar 09;14(2):e45 [FREE Full text] [doi: 10.2196/jmir.1922] [Medline: 22532074]

19. Dirmaier J, Härter M, Weymann N. A tailored, dialogue-based health communication application for patients with chronic low back pain: study protocol of a randomised controlled trial. BMC Med Inform Decis Mak 2013 Jun 14;13:66 [FREE Full text] [doi: 10.1186/1472-6947-13-66] [Medline: 23768119]

20. Weymann N, Härter M, Dirmaier J. A tailored, interactive health communication application for patients with type 2 diabetes: study protocol of a randomised controlled trial. BMC Med Inform Decis Mak 2013 Feb 13;13:24 [FREE Full text] [doi: 10.1186/1472-6947-13-24] [Medline: 23406466]

21. Lei H, Nahum-Shani I, Lynch K, Oslin D, Murphy SA. A "SMART" design for building individualized treatment sequences. Annu Rev Clin Psychol 2012;8:21-48 [FREE Full text] [doi: 10.1146/annurev-clinpsy-032511-143152] [Medline: 22224838]

22. Donkin L, Christensen H, Naismith SL, Neal B, Hickie IB, Glozier N. A systematic review of the impact of adherence on the effectiveness of e-therapies. J Med Internet Res 2011 Aug 05;13(3):e52 [FREE Full text] [doi: 10.2196/jmir.1772] [Medline: 21821503]

23. Richardson A, Graham AL, Cobb N, Xiao H, Mushro A, Abrams D, et al. Engagement promotes abstinence in a web-based cessation intervention: cohort study. J Med Internet Res 2013 Jan 28;15(1):e14 [FREE Full text] [doi: 10.2196/jmir.2277] [Medline: 23353649] 
24. Zeng Y, Liu X, Wang Y, Shen F, Liu S, Rastegar-Mojarad M, et al. Recommending Education Materials for Diabetic Questions Using Information Retrieval Approaches. J Med Internet Res 2017 Oct 16;19(10):e342 [FREE Full text] [doi: 10.2196/jmir.7754] [Medline: 29038097]

\author{
Abbreviations \\ AC: available cases \\ IA: information architecture \\ ITT: intention to treat \\ RCT: randomized controlled trial \\ T0, T1, T2, T3: baseline, time 1, time 2, time 3

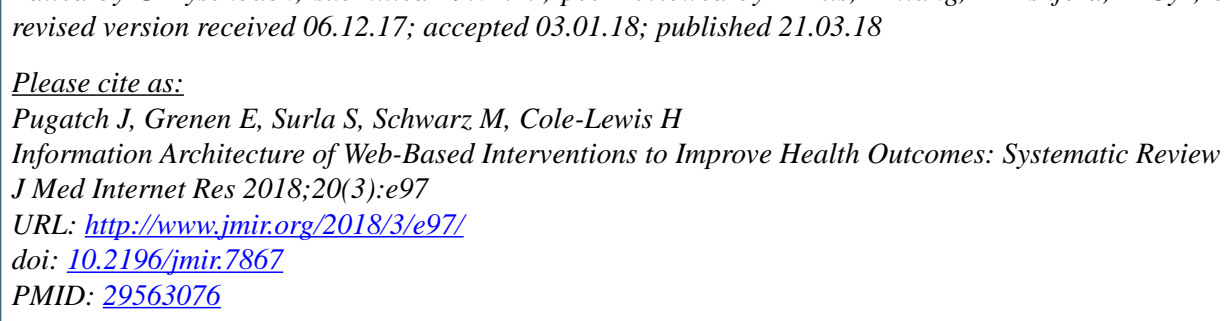

CJillian Pugatch, Emily Grenen, Stacy Surla, Mary Schwarz, Heather Cole-Lewis. Originally published in the Journal of Medical Internet Research (http://www.jmir.org), 21.03.2018. This is an open-access article distributed under the terms of the Creative Commons Attribution License (https://creativecommons.org/licenses/by/4.0/), which permits unrestricted use, distribution, and reproduction in any medium, provided the original work, first published in the Journal of Medical Internet Research, is properly cited. The complete bibliographic information, a link to the original publication on http://www.jmir.org/, as well as this copyright and license information must be included. 